\title{
Mesenchymal stem cells release exosomes that transfer miRNAs to endothelial cells and promote angiogenesis
}

\author{
Min Gong ${ }^{1,2}$, Bin Yu ${ }^{1}$, Jingcai Wang ${ }^{1}$, Yigang Wang ${ }^{1}$, Min Liu ${ }^{1}$, Christian Paul ${ }^{1}$, Ronald \\ W. Millard ${ }^{1,3}$, De-Sheng Xiao ${ }^{4}$, Muhammad Ashraf ${ }^{1,5}$ and Meifeng $\mathbf{X u}^{1}$ \\ ${ }^{1}$ Department of Pathology and Laboratory Medicine, University of Cincinnati Medical Center, Cincinnati, Ohio, USA \\ ${ }^{2}$ Children's Nutrition Research Centre, Children's Hospital of Chongqing Medical University, Chongqing, China \\ ${ }^{3}$ Department of Pharmacology and Cell Biophysics, University of Cincinnati Medical Center, Cincinnati, Ohio, USA \\ ${ }^{4}$ Department of Preventive Medicine, School of Public Health, Guangzhou Medical University, Guangzhou, Guangdong \\ Province, China \\ ${ }^{5}$ Department of Pharmacology, University of Illinois at Chicago, Chicago, Illinois, USA
}

Correspondence to: Meifeng Xu, email: Meifeng.xu@uc.edu

Keywords: exosomes, miRNA transfer, mesenchymal stem cells, angiogenesis, miR-30b

Received: December 19, $2016 \quad$ Accepted: March 21, $2017 \quad$ Published: April 01, 2017

Copyright: Gong et al. This is an open-access article distributed under the terms of the Creative Commons Attribution License 3.0 (CC BY 3.0), which permits unrestricted use, distribution, and reproduction in any medium, provided the original author and source are credited.

\section{ABSTRACT}

Mesenchymal stem cells (MSCs) have been found to benefit patients with a variety of ischemic diseases via promoting angiogenesis. It is also well established that exosomes secreted from MSCs deliver bioactive molecules, including microRNAs (miRs) to recipient cells. Therefore, we hypothesized that exosomes secreted from MSCs deliver miRs into endothelial cells and mediate angiogenesis. The pro-angiogenic stimulatory capacity of exosomes was investigated using tube-like structure formation and spheroid-based sprouting of human umbilical vein endothelial cells (HUVECs), and in vivo Matrigel plug assay. The secretion of pro-angiogenic miRs (pro-angiomiRs) from MSCs into culture medium and transfer of the miRs to HUVECs were confirmed using real-time quantitative PCR. Supplementation of the exosome secretion blocker GW4869 $(10 \mu \mathrm{M})$ reduced the pro-angiomiRs in the MSC-derived conditioned medium $\left(\mathrm{CdM}^{\mathrm{MSC}}\right)$. Addition of exosomes isolated from CdM ${ }^{\mathrm{MSC}}$ could directly 1) promote HUVEC tube-like structure formation in vitro; 2) mobilize endothelial cells into Matrigel plug subcutaneously transplanted into mice; and 3 ) increase blood flow inside Matrigel plug. Fluorescence tracking showed that the exosomes were internalized rapidly by HUVECs causing an upregulated expression of pro-angiomiRs in HUVECs. Loss-andgain function of the pro-angiomiRs (e.g., miR-30b) in MSCs significantly altered the pro-angiogenic properties of these MSC-derived exosomes, which could be associated with the regulation of their targets in HUVECs. These results suggest that exosomal transfer of pro-angiogenic miRs plays an important role in MSC mediated angiogenesis and stem cell-to-endothelial cell communication.

\section{INTRODUCTION}

It has been estimated that more than 500 million people will be benefited from various angiogenic therapies in the coming decades for treating ischemic diseases such as peripheral and coronary vascular disease [1], cerebral infarction [2], and critical limb ischemia [3]. Angiogenesis is a complex biological process involving interactions between vascular cells and the extracellular environment. Cell-based pro-angiogenic therapies have been increasingly utilized in the treatment of ischemic diseases $[4,5]$. Consequently, stem cells have been extensively used to experimentally treat ischemic diseases including myocardial infarction $[6,7]$ and stroke $[8,9]$. Mesenchymal stem cells (MSCs) have been recognized as a promising treatment option with the potential to generate a variety of useful cell-based interventions $[10,11]$ and pro-angiogenic therapies $[12,13]$. Indeed, both in vitro and in vivo models have shown that MSCs can increase endothelial cell growth and enhance new blood vessel formation [14], as a result of paracrine effects that are considered as the predominant mechanism in addressing 
tissue damage [15]. We previously demonstrated that conditioned medium (CdM) of MSCs promoted postinfarction angiogenesis in ischemic myocardium and global heart function recovery [16]. However, the exact molecular mechanisms responsible for these beneficial paracrine effects of MSCs have not been identified.

Exosomes are cell-derived vesicles (diameter 30-100 nm) that exist in almost all biological fluids including blood, urine, saliva, cerebrospinal fluid, and cell preconditioned medium $[17,18]$. They are initially formed by fusion of a multi-vesicular body with a plasma membrane, or released directly from the plasma membrane $[17,19]$. Exosomes shuttle mRNAs, miRs, and other molecular constituents to achieve cell-to-cell communication, and modulate the function of recipient cells [20]. However, exosomes contents vary from different cell types, pathological conditions and by preconditioning or genetic manipulation of the parent MSCs [21, 22], which might cause completely inversed fate of target cells.

Most recently, the existence of miRs in exosomes has been reported [23-25], suggesting that exosomes may serve as a vehicle for miR transfer and mediate intercellular communication [26]. MiRs, a class of small non-coding RNAs (containing about 18-22 nucleotides), regulate gene expression on the posttranscriptional level by binding to specific mRNA and inducing their degradation and/or translational inhibition [27]. MiRs are recognized to participate in a wide range of biological and pathological processes including the cell cycle, hematopoiesis, neurogenesis, aging, cancer, and cardiovascular disease [28]. Evidence has suggested that miRs are key regulators of endothelial cell function and are especially important modulators of angiogenesis [29]. For instance, it has been reported that miR-424 promoted angiogenesis in vitro and in a mouse model by targeting cullin 2 [30]. miR-30 family targeted DLL4 in endothelial cells to promote angiogenesis [31]. The present study was designed to investigate whether MSC-derived exosomes shuttle various pro-angiogenic miRs and transfer these miRs to endothelial cells resulting in promoting angiogenesis.

\section{RESULTS}

\section{Pro-angiogenic capacity of conditioned medium derived from MSCs}

MSCs line C3H10T1/2 cells were purchased from ATCC (Manassas, VA, USA). MSCs adhered to the surface of plastic culture dishes and exhibited a spindle-shaped fibroblast-like morphology as shown in the Supplementary Figure 1. The pro-angiogenic capacity of CdM obtained from these cells $\left(\mathrm{CdM}^{\mathrm{MSC}}\right)$ was assessed using tube-like structure formation, spheroid-based sprouting of HUVECs and in vivo Matrigel plug assay. The cumulative tube length was significantly longer $(31.80 \pm 3.37 \mathrm{~mm} /$ field $)$ in HUVECs treated with $\mathrm{CdM}^{\mathrm{MSC}}$ compared to those treated with control medium $(18.69 \pm 2.83 \mathrm{~mm} /$ field $)$ following culture for $16 \mathrm{~h}$ (Figure 1A). Sprout length per spheroid in HUVECs treated with $\mathrm{CdM}^{\mathrm{MSC}}$ for $16 \mathrm{~h}$ was significantly longer $(216.67 \pm 36.29 \mu \mathrm{m} /$ spheroid $)$ than that treated with control medium (82.66 $\pm 32.23 \mu \mathrm{m} /$ spheroid) (Figure 1B). The effect of $\mathrm{CdM}^{\mathrm{MSC}}$ on endothelial cell invasion and hemoglobin concentration in Matrigel plug was investigated following subcutaneous injection of Matrigel into C57BL6 mice. The Matrigel plug contained $\mathrm{CdM}^{\mathrm{MSC}}$ had a red gross appearance after transplanting for 14 days (Figure 1C). The hemoglobin content (a sign of increased new vessel formation) was significantly increased in the plugs containing $\mathrm{CdM}^{\mathrm{MSC}}$ (11.14 \pm $5.01 \mu \mathrm{g} / \mathrm{mg}$ plug) compared to the Matrigel plugs without $\mathrm{CdM}^{\mathrm{MSC}}(2.48 \pm 1.19 \mu \mathrm{g} / \mathrm{mg}$ plug) (Figure 1D). The neovasculature visualized by immunofluorescence staining of CD31 indicated that the number of CD31 positive cells in the plugs containing $\mathrm{CdM}^{\mathrm{MSC}}$ was significantly higher than that without $\mathrm{CdM}^{\mathrm{MSC}}$ (Figure 1E).

\section{miRs secreted from MSCs transfer to HUVECs}

The expression of 26 most commonly acknowledged pro-angiogenic miRs (pro-angiomiRs) in $\mathrm{CdM}^{\mathrm{MSC}}$ was quantified using real-time PCR before and after adding into HUVEC culture. The expression of miR-424, miR-30c, miR-30b, and let-7f in conditioned medium was significantly reduced after adding into HUVECs culture for $48 \mathrm{~h}$, indicating that extracellular miRs, derived from MSCs, transferred into HUVECs. Meanwhile, the expression of miR-21, miR-10a, miR126, miR-10b, miR-19a, miR-19b was significantly increased after adding into HUVECs culture, suggesting that HUVECs might release these miRs (Table 1). The expression of other miRs was either very low in $\mathrm{CdM}^{\mathrm{MSC}}$ or the change was not significant (Supplementary Table 1).

Next, the transfer of miRs between MSCs and HUVECs was determined using a non-contact co-culture system. The CdM was collected from MSC-HUVEC co-culture $\left(\mathrm{CdM}^{\mathrm{MSC}-\mathrm{HUVEC}}\right)$ and its controls, MSC-MSC co-culture (CdM $\left.{ }^{\mathrm{MSC}-\mathrm{MSC}}\right)$ and HUVEC-HUVEC coculture $\left(\mathrm{CdM}^{\mathrm{HUVEC}-\mathrm{HUVEC}}\right)$, respectively. The expression of miR-30b, 30c, 424 and let-7f in CdM HUVEC-HUVEC $^{\text {was }}$ very low and in $\mathrm{CdM}^{\mathrm{MSC}-\mathrm{MSC}}$ was very high. However, the expression of these miRs in $\mathrm{CdM}^{\mathrm{MSC}-H U V E C}$ was

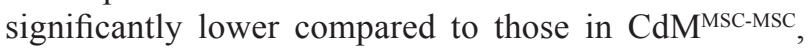
indicating that these miRs transferred into HUVECs (Figure 2A). Moreover, the expression of these miRs in HUVECs co-cultured with MSCs was significantly higher than in those without co-cultured with MSCs (Figure 2B), directly demonstrating a transfer of these miRs into HUVECs. 


\section{Exosomes derived from MSCs deliver pro- angiomiRs and promote angiogenesis}

To investigate whether exosomes mediated miRs transfer, the expression of miRs in CdM was measured after MSCs were treated with $10 \mu \mathrm{M}$ GW4869 (an exosome release inhibitor) for $48 \mathrm{~h}$ [32]. As shown in Figure 3A, the levels of miR-30b, $-30 \mathrm{c},-424$, and let-7f in the CdM collected from MSCs treated with GW4869 $\left(\mathrm{CdM}^{\mathrm{GW} 4869}\right)$ were significantly decreased compared with CdM obtained from control MSCs. In addition, the expression of these miRs in HUVECs treated with $\mathrm{CdM}^{\mathrm{GW} 4869}$ for $48 \mathrm{~h}$ was also significantly decreased compared to those treated with $\mathrm{CdM}^{\mathrm{MSC}}$ (Figure 3B), indicating that exosomes mediated miR transportation between MSCs and HUVECs. Exosomes, isolated from $\mathrm{CdM}^{\mathrm{MSC}}$, exhibited the characteristic round morphology with heterogeneous size under transmission electron microscope (Figure 4A). The average size of exosomes was $48.72 \pm 2.7 \mathrm{~nm}$ according to the results of dynamic light scattering (Figure 4B). The expression of CD9, CD63, and HSP70 was significantly higher in exosomes compared to their parent MSCs (Figure 4C). The internalization of exosome pre-labeled with PKH26 by HUVECs was recorded using IncuCyte ZOOM Live Content Imaging System every $2 \mathrm{~h}$ for $12 \mathrm{~h}$. The PKH26 red fluorescence intensity increased with the passage of time and achieved its maximum after exosomes were added into HUVECs culture for $10 \mathrm{~h}$ (Figure 4D). The expression of miR-30b, 30c, 424, and let-7f in HUVECs treated with exosomes for $24 \mathrm{~h}$ was significantly increased compared to those treated with BSA (Figure 4E).
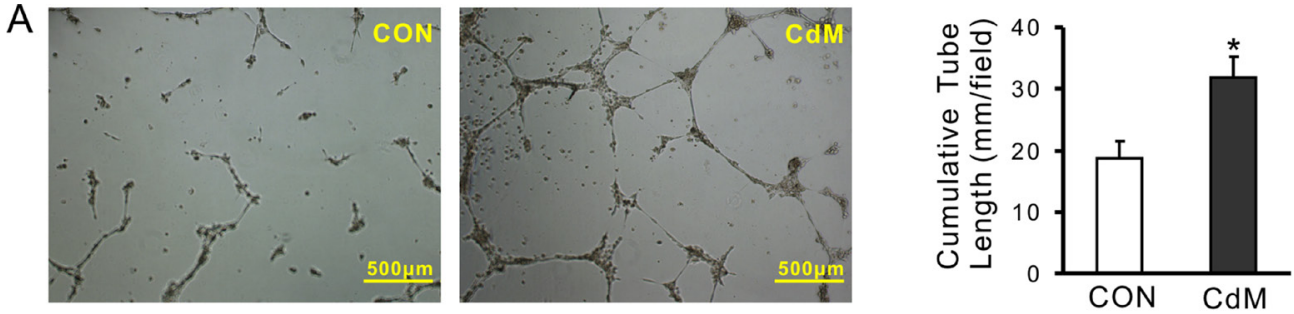

B
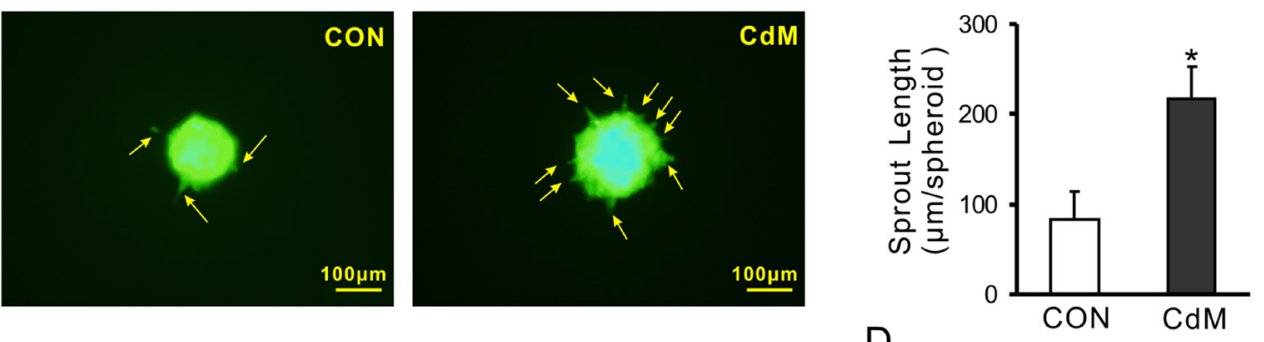

C
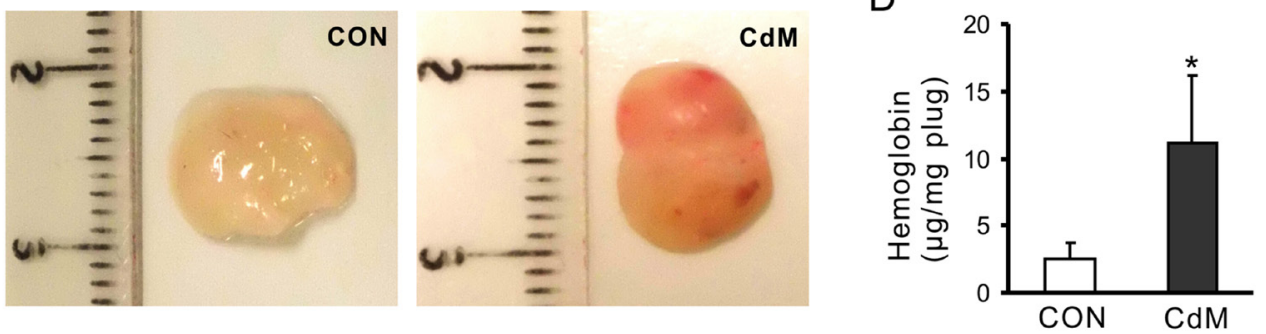

E
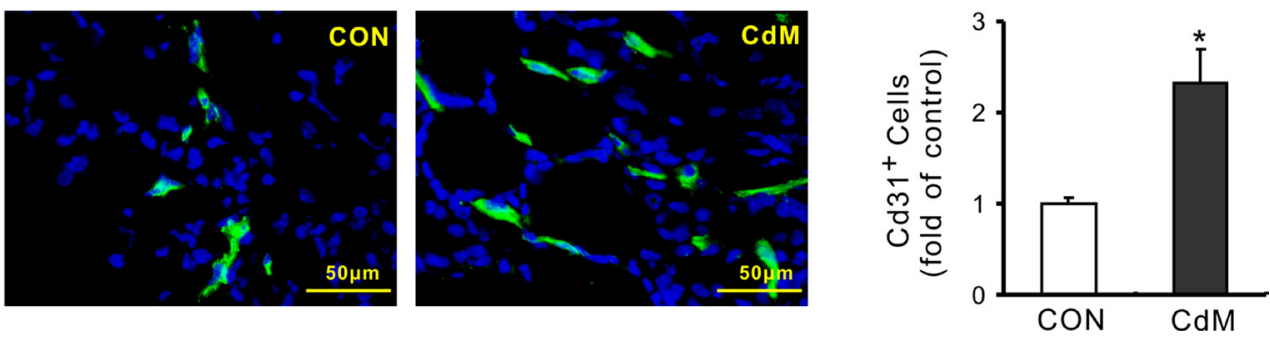

Figure 1: CdM derived from MSCs promotes angiogenesis. (A) Representative images of capillary-like structures and quantitative analysis of the total tube length (4× magnification microscopic fields); (B) Representative images of HUVEC spheroids sprouting and quantitative analysis of the cumulative sprout length per spheroid; (C) Representative gross look of Matrigel plugs which were implanted subcutaneously in mice for 14 days; (D) Hemoglobin content in the Matrigel plugs; (E) The neovasculature in Matrigel was visualized by immunofluorescence staining of CD31. Quantification of the CD31-positive cells in Matrigel plugs were determined by pixel density $(* P<0.05$ vs $\mathrm{CON})$. 
Table 1: The expression of pro-angiogenic miRNAs in $\mathrm{CdM}^{\mathrm{MSC}}$ after adding into HUVECs culture for 48 hours

\begin{tabular}{|c|c|c|c|c|c|}
\hline \multicolumn{3}{|c|}{ Downregulated } & \multicolumn{3}{|c|}{ Upregulated } \\
\hline miRNA & $\mathrm{CdM}^{\mathrm{MSC}} 2^{(-\Delta \mathrm{Ct})}$ & CdM MSC with HUVECs $2^{(-\Delta C t)}$ & miRNA & $\mathrm{CdM}^{\mathrm{MSC}} 2^{(-\Delta \mathrm{Ct})}$ & CdM ${ }^{\mathrm{MSC}}$ with HUVECs $2^{(-\Delta C t)}$ \\
\hline $\operatorname{miR}-424^{\#}$ & $44.965 \pm 5.542$ & $10.725 \pm 1.795^{*}$ & miR-21 & $89.021 \pm 9.117$ & $187.956 \pm 27.620^{*}$ \\
\hline miR-30c & $6.420 \pm 0.623$ & $0.572 \pm 0.140^{*}$ & miR-10a & $0.435 \pm 0.040$ & $10.160 \pm 0.985^{*}$ \\
\hline miR-30b & $5.877 \pm 0.692$ & $0.133 \pm 0.012^{*}$ & miR-126 & $0.045 \pm 0.014$ & $6.988 \pm 0.933^{*}$ \\
\hline let-7f & $4.592 \pm 0.245$ & $0.153 \pm 0.003^{*}$ & miR-10b & $0.008 \pm 0.002$ & $5.869 \pm 0.442^{*}$ \\
\hline & & & miR-19a & $1.623 \pm 0.063$ & $3.380 \pm 0.316^{*}$ \\
\hline & & & miR-19b & $1.540 \pm 0.116$ & $2.950 \pm 0.225^{*}$ \\
\hline
\end{tabular}

$\left(* P<0.05\right.$ vs $\left.\mathrm{CdM}^{\mathrm{MSC}}\right)$.

\#The mouse homologue of miR-424 sequence from human is miR-322-5p.

The pro-angiogenic capacity of exosomes was examined in vitro and in vivo. The cumulative tube length was significantly increased in HUVECs treated with exosomes $(100 \mu \mathrm{g} / \mathrm{ml})$ for $16 \mathrm{~h}(36.24 \pm 3.65 \mathrm{~mm} /$ field $)$ compared to that treated with BSA in the same protein amount (15.73 $\pm 2.44 \mathrm{~mm} /$ field) (Figure 5A). The Matrigel plug test showed a more red appearance in those containing exosomes $(100 \mu \mathrm{g})$ after being transplanted for 14 days than those without exosomes (Figure 5B). The hemoglobin concentration in the plugs containing exosomes was significantly higher $(11.76 \pm 5.61 \mu \mathrm{g} / \mathrm{mg}$ plug $)$ than those without exosomes $(2.54 \pm 1.45 \mu \mathrm{g} / \mathrm{mg}$ plug $)$ (Figure 5C). The immunofluorescence staining showed that the number of CD31 positive cells in the plugs containing exosomes was also significantly higher than those without exosomes (Figure 5D).

To demonstrate the effect of transferred miRs on angiogenesis, miR-30b was selected as a representative miR. Exosomes were obtained from MSCs in which miR-30b was overexpressed or knockdown, respectively. MSCs were infected with lentivirus carrying the pre-miR$30 \mathrm{~b}$ fragment $\left(\mathrm{MSC}^{\mathrm{miR}-30 \mathrm{~b}}\right)$. The expression of miR-30b in $\mathrm{MSC}^{\mathrm{miR}-30 \mathrm{~b}}$ and exosomes derived from $\mathrm{MSC}^{\mathrm{miR}-30 \mathrm{~b}}$ (Exo ${ }^{\mathrm{miR}-}$ ${ }^{30 b}$ ) was 5.24-fold and 5.22-fold increase compared with their counterpart $\mathrm{MSC}^{\text {scrambled }}$ and $\mathrm{Exo}^{\text {scrambled }}$, respectively (Figure 6A). The cumulative tube length was increased in
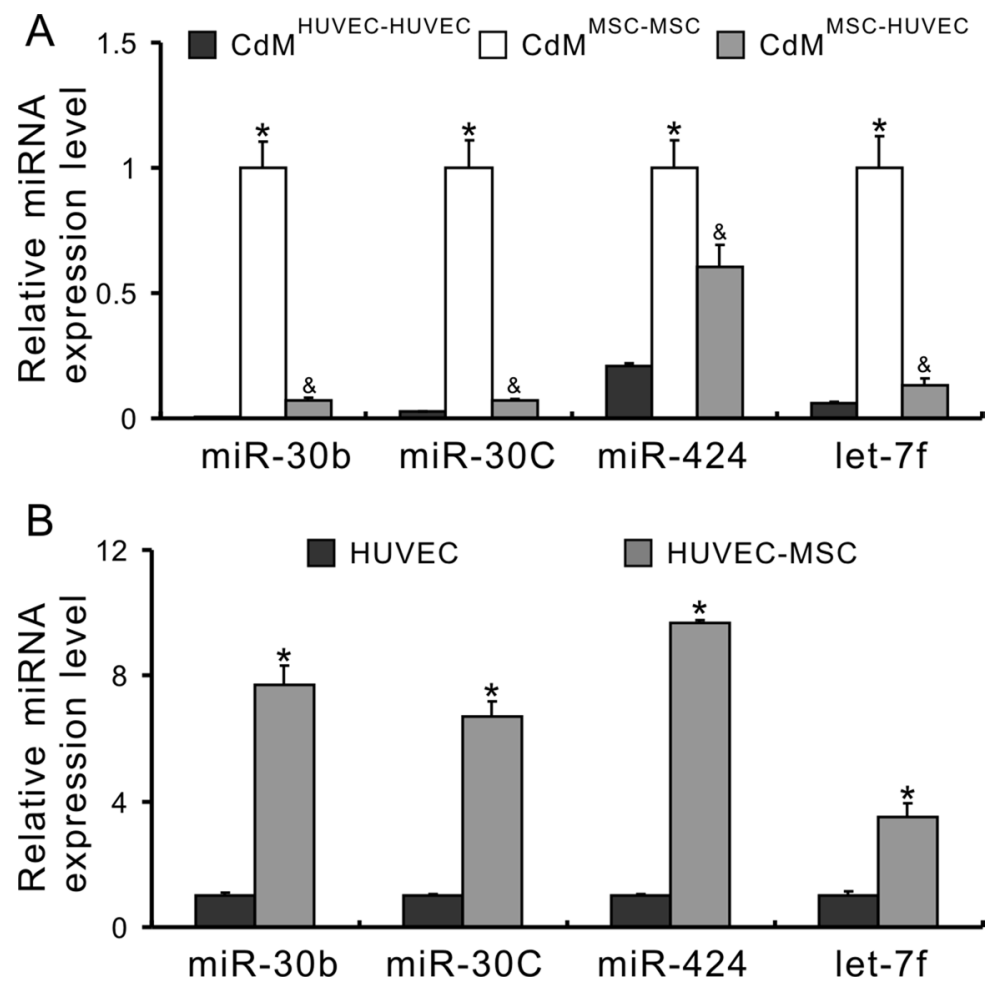

Figure 2: miRs secreted from MSCs transfer to HUVECs. (A) miRNA expression in the CdM of non-contact cell co-culture system $\left(* P<0.05\right.$ vs $\mathrm{CdM}^{\text {HUVEC-HUVEC}}$; $P<0.05$ vs $\mathrm{CdM}^{\mathrm{MSC}-\mathrm{MSC}}$, respectively); (B) The expression of miRs in HUVECs after co-culture with MSCs $(* P<0.05$ vs HUVEC alone). 

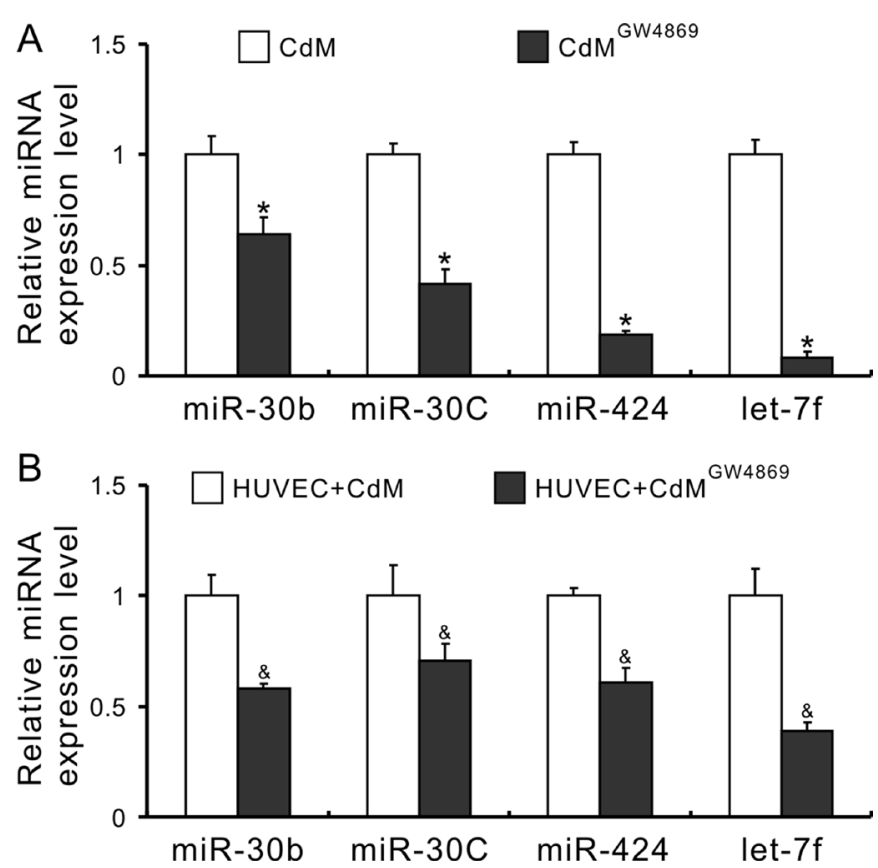

Figure 3: Exosomes mediate the transfer of miRs from MSCs to HUVECs. (A) The expression of miRs in $\operatorname{CdM}(* P<0.05$ vs $\left.\mathrm{CdM}^{\mathrm{MSC}}\right)$; (B) The expression of miRs in HUVECs treated with CdM $\left({ }^{\circledR} P<0.05\right.$ vs $\left.\mathrm{HUVEC}+\mathrm{CdM}^{\mathrm{MSC}}\right)$.
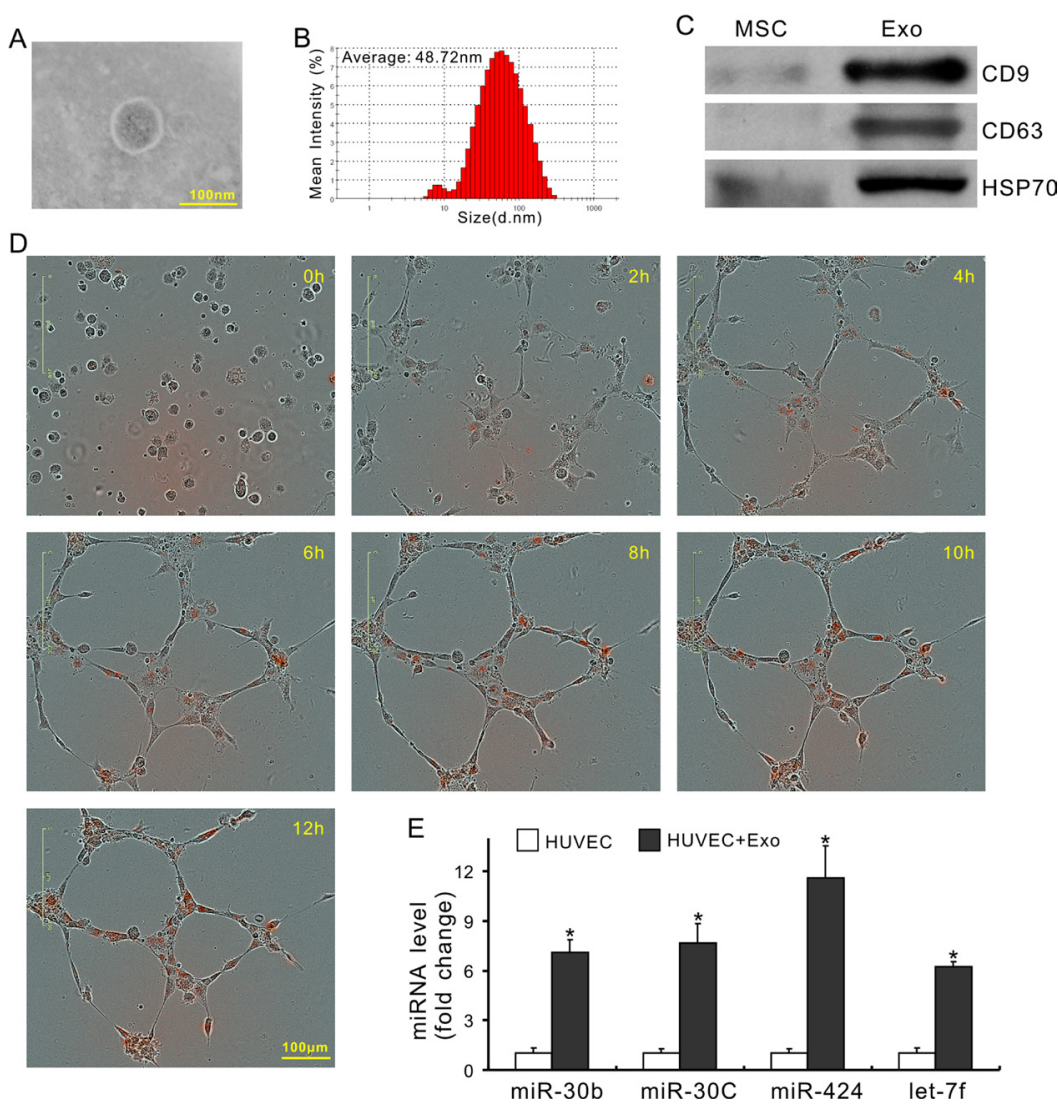

Figure 4: Characterization of exosomes and their involvement in miRs transfer. (A) Morphology of exosomes under transmission electron microscopy; (B) The exosome size was measured using a Zetasizer Nano instrument. (C) The expression of CD9, CD63 and HSP70; (D) Representative images of time-lapse internalization of PKH26-labled exosomes (red) in HUVECs. (E) miR expression in HUVECs following exosome treatment $\left({ }^{*} P<0.05\right.$ vs HUVEC+ BSA). 
HUVECs treated with Exo ${ }^{\mathrm{miR}-30 \mathrm{~b}}(54.98 \pm 9.89 \mathrm{~mm} /$ field $)$ compared to HUVECs treated with Exo $^{\text {scrambled }}(32.81 \pm 4.68$ $\mathrm{mm} /$ field), indicating that overexpression of miR-30b enhanced the pro-angiogenic capacity of exosomes (Figure 6B). In another set of experiment, miR-30b was downregulated using synthetic anti-miR-30b in MSCs $\left(\mathrm{MSC}^{\text {anti-miR-30b }}\right)$. The expression of miR-30b in MSC ${ }^{\text {anti-miR-30b }}$ and exosomes derived from these cells $\left(\mathrm{Exo}^{\mathrm{anti}-\mathrm{miR}-30 \mathrm{~b}}\right)$ was significantly reduced, compared with their counterpart $\mathrm{MSC}^{\mathrm{NTC}}$ and $\mathrm{Exo}^{\mathrm{NTC}}$, respectively (Figure 6C). The cumulative tube length was significantly decreased in HUVECs treated with Exo ${ }^{\text {anti-miR-30b }}(25.68 \pm 3.49 \mathrm{~mm} /$ field $)$ compared to those treated with $\operatorname{Exo}^{\mathrm{NTC}}(35.42 \pm 3.01 \mathrm{~mm} /$ field) (Figure 6D), indicating that downregulation of miR$30 \mathrm{~b}$ reduced the pro-angiogenic capacity of exosomes. Finally, HUVECs were directly infected with miR-30b (HUVEC $^{\text {miR-30b }}$ ) using lentivirus carrying pre-miR-30b fragment (Figure 7A). The expression of miR-30b in HUVECs was verified by real-time PCR (Figure 7B). The cumulative tube length was increased in HUVEC ${ }^{\text {miR-30b }}$ (29.88 $\pm 4.51 \mathrm{~mm} /$ field) compared to that in HUVECs infected with scrambled-miR (HUVEC ${ }^{\text {scrambled, }} 17.61 \pm$ $4.28 \mathrm{~mm} /$ field) (Figure 7C). TargetScan shows that the 3' UTR of DLL4 contains the conserved miR-30 family binding sites (Figure 7D). The expression of DLL4 in HUVEC $^{\text {miR-30b }}$ was significantly reduced, compared to that in HUVEC ${ }^{\text {scrambled }}$ (Figure 7E and 7F).

\section{DISCUSSION}

In this study, we investigated whether the paracrine mechanism by which MSCs promote angiogenesis is associated with exosome-mediated miRs transfer. Our data indicate that: 1) The conditioned medium of MSCs significantly increased tube-like structure formation, spheroid-based sprouting and neo-angiogenesis in Matrigel plug; 2) Exosomes derived from MSCs mediated the transfer of miRs from MSCs to HUVECs and promoted angiogenesis; and 3) Gain-and-loss function of miRs in exosomes demonstrated that the pro-angiogenic effect of exosomes is dependent on their pro-angiomiRs cargo.

MSCs have been considered as ideal candidates for cell-based pro-angiogenic therapy. It has been identified that MSCs secrete a variety of bioactive components including proteins, cytokines, chemicals, etc. [33, 34]. Our results demonstrated that conditioned medium of MSCs promoted HUVEC mediated tube-like structure formation, increased sprouts from HUVECs spheroids, attracted endothelial cell migration, and promoted endothelial cell proliferation (Supplementary Figure 2). These findings that MSCs promote angiogenesis through paracrine mechanisms are consistent with previous reports $[35,36]$.

Several miRs have been considered to participate in the regulation of various aspects of angiogenesis, including proliferation, migration and morphogenesis
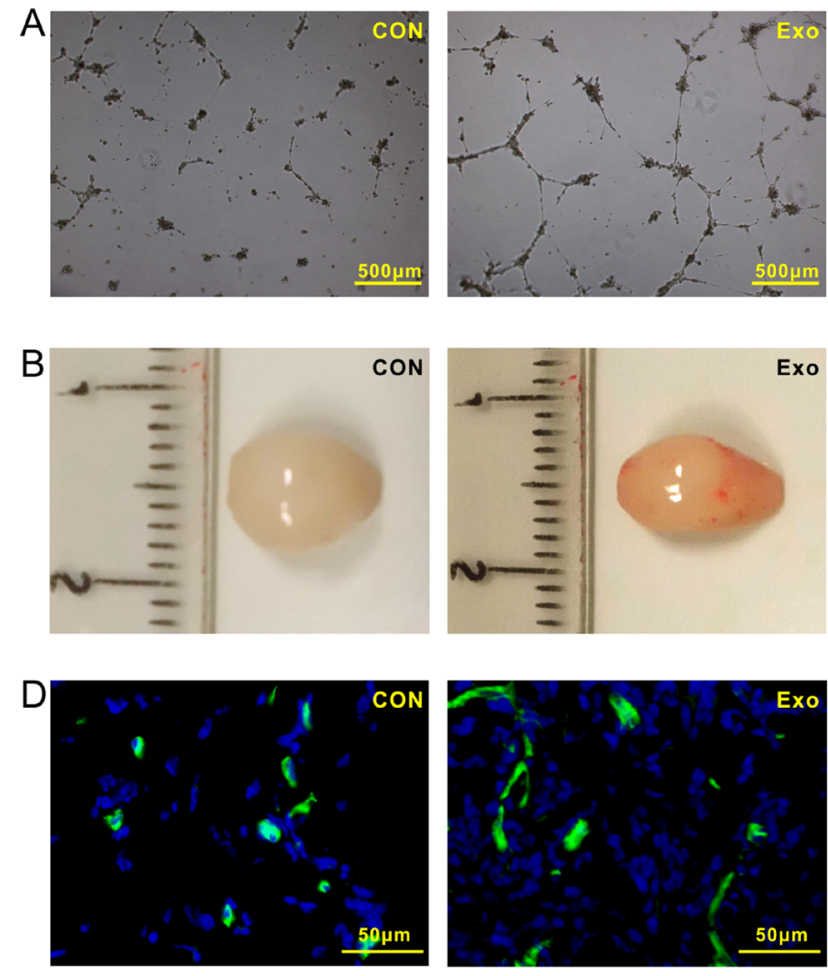
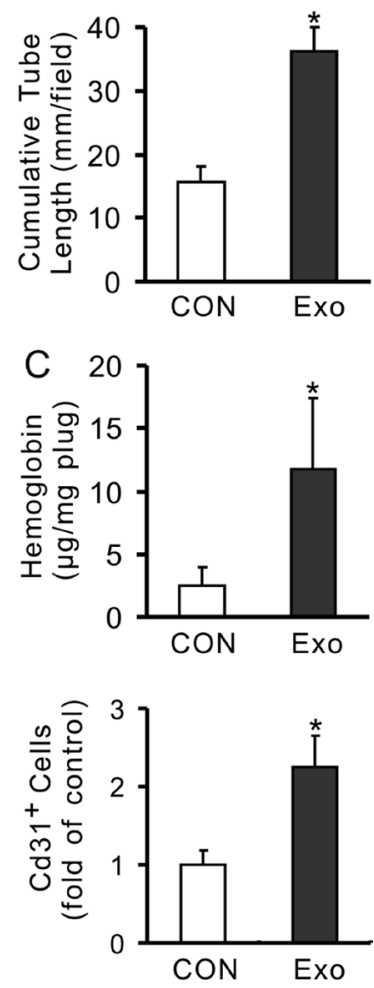

Figure 5: Exosomes derived from MSCs promote angiogenesis. (A) Representative images of tube-like structures and quantitative analysis of the total tube length (4× magnification microscopic fields); (B) Representative gross look of Matrigel plugs; (C) Hemoglobin content in the Matrigel plugs; (D) Immunofluorescence staining of CD31 in the sections of Matrigel plugs and quantification of the CD31positive cells $(* P<0.05$ vs $\mathrm{CON})$. 
of endothelial cells $[30,31,37,38]$. Pro-angiomiRs promote angiogenesis by targeting different regulators in angiogenic signaling pathways [29]. In this study, the expression of 26 pro-angiomiRs was quantified in $\mathrm{CdM}^{\mathrm{MSC}}$ and screened out that miR-30b, miR-30c, miR-424 and let-7f were implicated in MSC-mediated angiogenesis. Moreover, the expression of these miRs in HUVECs was significantly increased following treatment with $\mathrm{CdM}^{\mathrm{MSC}}$. All of these results indicate that the extracellular proangiomiRs derived from MSCs indeed transferred into HUVECs. Therefore, the angiogenetic effects of MSCs may be related to the secretion of pro-angiomiRs and transfer of these miRs into endothelial cells.

Recently, it has been shown that exosomes secreted from MSCs play a critical role in MSC-mediated paracrine effects via transfer of miRs [39]. Extracellular miRs exist with remarkable stability in various types of body fluids and cell culture media in the vesicle-associated form [40]. To confirm whether exosomes act as a vehicle for miRs carriage and transfer, we first used GW4869 to inhibit the exosomes secretion. GW4869 controls ceramide synthesis and regulates the secretion of exosomes [32]. Our results indicated that GW4869 significantly reduced the secretion of pro-angiomiRs from MSCs into culture medium. The expression of these pro-angiomiRs was also reduced in HUVECs treated with $\mathrm{CdM}^{\mathrm{GW} 4869}$. Moreover, the pro-angiogenic capacity of $\mathrm{CdM}^{\mathrm{MSC}}$ was reduced after inhibiting or depleting exosomes in the CdM (Supplementary Figure 3), which was consistent with previous reports $[41,42]$. These results revealed that the angiogenic effect of CdM was at least partly attributable to exosomes and that inhibition of exosome secretion decreased the transfer of miRs resulting in inhibition of angiogenesis.

The pro-angiogenic capacity of exosomes derived from MSCs was directly investigated through in vitro and in vivo studies. It is reported that exosomes contain plenty of miRs, including pro-angiomiRs (miR-21, miR-126, miR-130a, miR-132, miR-210, miR-378 and let-7f, etc.) $[21,43,44]$. To determine the role of transferred proangiomiRs in angiogenesis, we selected miR-30b amongst the cluster of miRs (miR-30b, 30c, 424 and let-7f) discovered in this study for gain-and-loss function in MSCs. Infecting MSCs with miR-30b not only upregulated the expression of miR-30b in MSCs, but also increased its expression in exosomes derived from these cells. Treatment of HUVECs with these exosomes significantly promoted tube-like structure formation. In contrary, inhibiting expression of miR-30b in exosomes resulted in reduced angiogenesis. These results indicate that miR-30b carried by exosomes plays an important role in MSCs mediated angiogenesis. Previous studies reported that DLL4, one of miR-30 family targets, modulates endothelial cell behavior during angiogenesis $[31,45]$. DLL4 is a membrane-bound ligand belonging to the Notch signaling family and negatively regulates vascular sprouting and vessel branching [46, 47]. Our study showed that DLL4 expression in HUVECs ${ }^{\text {miR-30b }}$
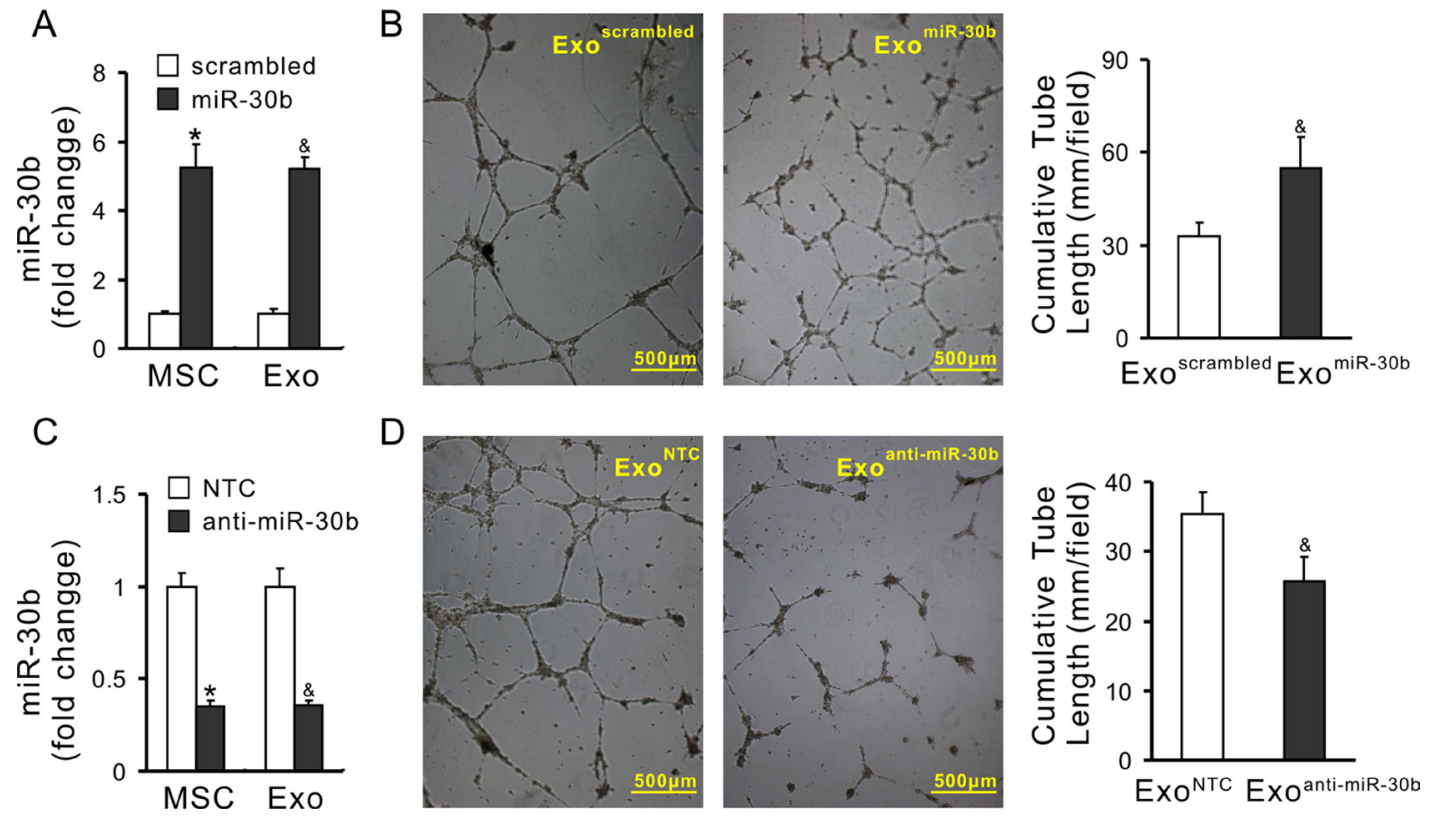

Figure 6: Pro-angiogenic properties of exosomes is associated with the expression of miRs. (A) The expression of miR-30b in $\operatorname{MSC}^{\text {miR-30b }}\left({ }^{*} P<0.05 v s\right.$ MSC $\left.^{\text {scrambled }}\right)$ and in exosomes derived from $\operatorname{MSC}^{\text {miR-30b }}$ (Exo ${ }^{\text {miR-30b }}{ }^{\&}\left({ }^{\&}, P<0.05 v s\right.$ Exo $\left.{ }^{\text {scrambled }}\right)$; (B) Representative images of capillary-like structures and quantitative analysis of the total tube length (4× magnification microscopic fields) ( ${ }^{\&} P<0.05$ $v s$ Exo $\left.^{\text {scrambled }}\right)$; (C) The expression of miR-30b in $\mathrm{MSC}^{\text {anti-miR-30b }}\left({ }^{*} P<0.05 v s \mathrm{MSC}^{\mathrm{NTC}}\right)$ and in Exo ${ }^{\text {anti-miR-30b }}\left({ }^{\&} P<0.05 v s\right.$ Exo $\left.{ }^{\mathrm{NTC}}\right)$; $(\mathbf{D})$ Representative images of tube-like structures in HUVECs and quantitative analysis of the total tube length (4× magnification microscopic fields) $\left({ }^{\&} P<0.05 v s \mathrm{Exo}^{\mathrm{NTC}}\right)$. 
was significantly reduced. It has been noted that there are many other pro-angiogenic miRs in the MSC-exosomes besides $26 \mathrm{miRs}$ mentioned here. It is possible that these pro-angiogenic miRs may play some roles in angiogenesis. In addition, exosomes derived from MSCs contain many growth factors, cytokines, and chemokines which may also participate in angiogenesis.

In this study, we used medium and BSA as control for $\mathrm{CdM}^{\mathrm{MSC}}$ and exosomes, respectively. It is well known that the CdM and the contents of exosomes are much more complicated than a simple medium or BSA. Therefore a CdM from a non-MSC cell line would be more appropriate for comparison. However, it is difficult to screen one suitable non-MSC cell as control cell, since the contents of CdM and exosome derived from other cells are also very complex. They may contain different proangiogenic factors or other factors, which may variably affect the angiogenesis more or less. It is noted that several previous studies also used basal medium as a control in their studies. van Balkom BW et al. [48] included basal medium as control to CdM derived from human microvascular endothelial cell line. Zhang B et al. [49] used PBS as control for exosomes derived from human umbilical cord mesenchymal stem cells and Wang X et al. [50] used medium as control for exosomes derived from cardiomyocytes.

It is well established that MSCs have a proangiogenic effect. However, from a translational perspective, exosomes derived from MSCs have shown encouraging therapeutic effects in various animal models as well in clinical trials [51]. The use of viable cells carries inherent risks such as microvasculature obstruction, transdifferentiation into inappropriate cell types, immune rejection, proarrhythmic side effects, and ossifications and/or calcifications [52]. Exosomes derived from MSCs eliminate many of these concerns associated with using live cells. In addition, the manufacture of cellbased therapeutics is also a challenging technology [52].
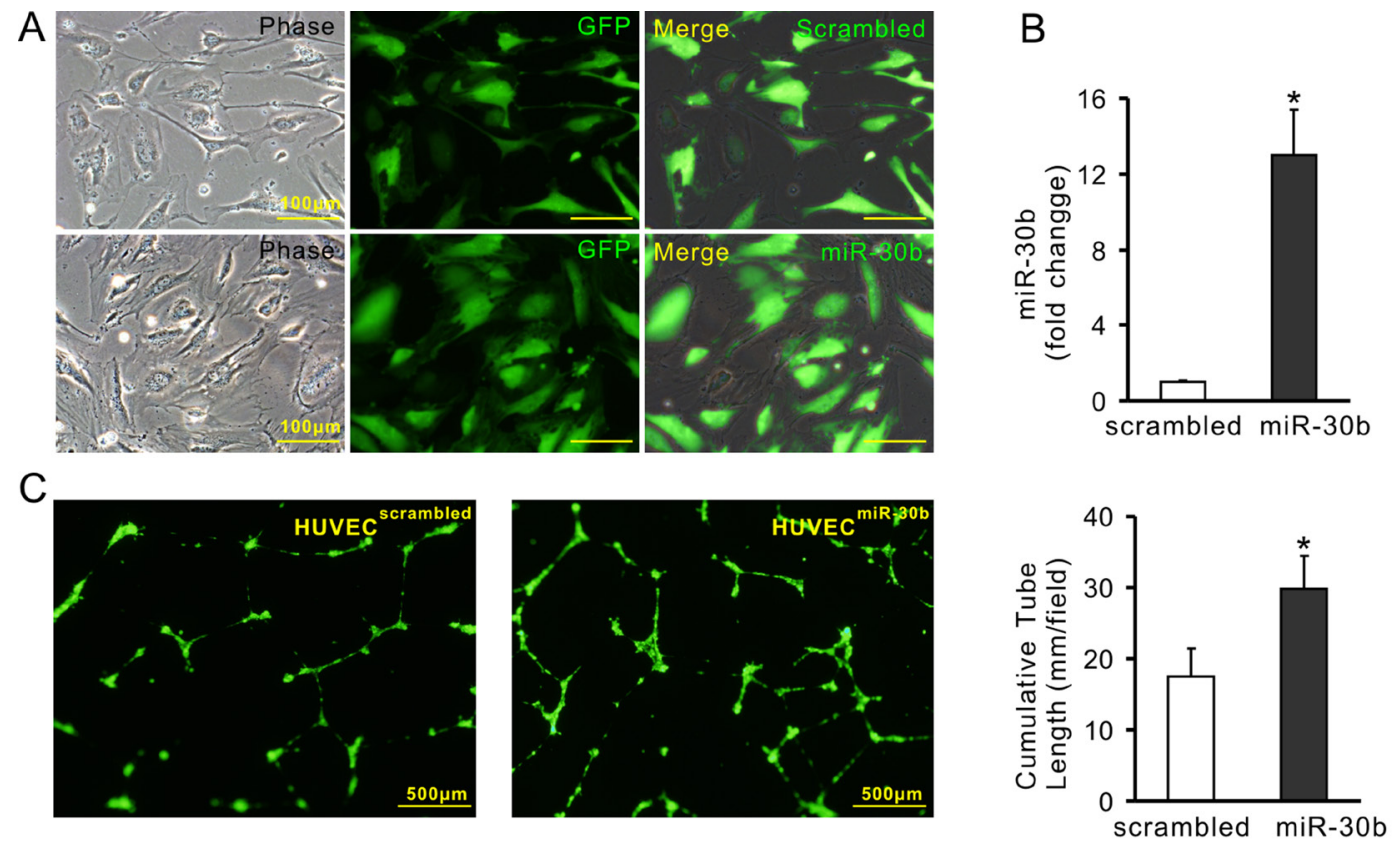

D
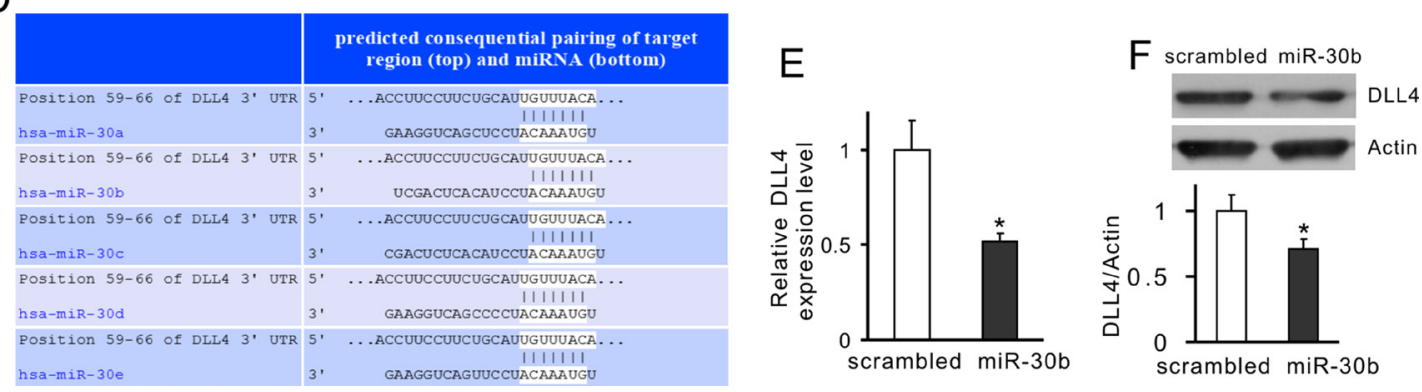

Figure 7: Overexpression of miR-30b downregulates DLL4 expression in HUVECs. (A) Representative images of HUVECs with miR-30b overexpression (HUVEC ${ }^{\text {miR-30b }}$ ) and their negative control (HUVEC $\left.{ }^{\text {scrambled}}\right)$; (B) The expression of miR-30b; (C) Representative images of tube-like structures and quantitative analysis of the total tube length (4× magnification microscopic fields); (D) TargetScan shows that 3' UTR of DLL4 contains conserved miR-30 family binding sites; (E and F) The expression of DLL4 in HUVECs (mRNA and protein, respectively) $\left(* P<0.05\right.$ vs HUVEC $\left.^{\text {scrambled }}\right)$. 
In contrast, exosomes can be easily stored at $-20^{\circ} \mathrm{C}$ for 6 months without loss of biological activity [53]. Therefore, exosome-based, cell-free therapies in regenerative medicine can be easier to manufacture and prima facie safer [53].

In conclusion, our studies suggest that the MSCs promote angiogenesis via secreting exosomes that deliver pro-angiomiRs and regulate their targets in recipient cells. MSC-derived exosomes could be considered for using in therapeutic angiogenesis especially for ischemic diseases.

\section{MATERIALS AND METHODS}

\section{Animals}

The University of Cincinnati Institutional Animal Care and Use Committee pre-approved all animal experiments. C57BL6 mice were housed under specific pathogens free (SPF) laboratory conditions and maintained under optimal temperature, humidity, photoperiods (12L: 12D) with food and water ad libitum.

\section{Concentration of conditioned medium ( $\mathrm{CdM}$ ) and collection of exosomes}

MSCs were first seeded at $3 \times 10^{6}$ per $15-\mathrm{cm}$ plate in complete DMEM/F12 medium for $24 \mathrm{~h}$. Then the medium was replaced with $15 \mathrm{ml}$ of serum-free medium. After being cultured for $48 \mathrm{~h}$, the medium was collected and centrifuged to remove cell debris. The supernatant was filtered through a $0.45-\mathrm{mm}$ PVDF filter (Millipore) and centrifuged $3,200 \mathrm{~g}$ at $4^{\circ} \mathrm{C}$ for 45 minutes, and then transferred into ultra-filtration conical tubes (Thermo Scientific ${ }^{\mathrm{TM}}$ Pierce) to concentrate medium to $100 \times$.

Exosomes were isolated from concentrated CdM using an ExoQuick-TC Exosome Precipitation Solution (System Biosciences) following instructions provided in the manual [54]. Exosome pellets were resuspended with DMEM medium and stored at $-80^{\circ} \mathrm{C}$ for use. The quantity of exosomes was expressed as exosome-associated proteins, using the BCA method (Thermo Fisher Scientific). The quality of exosomes was confirmed by dynamic light scattering using a particle and molecular size analyzer (ZetasizerNano ZS, Malvern Instruments) according to the manufacturer's instructions. The expression of CD9, CD63 and HSP70 was quantified using western blotting.

The morphology of exosomes was observed under transmission electron microscope (JEOL JEM-1230) as described previously [54]. In brief, exosomes were fixed with $2 \%$ paraformaldehyde and $2 \%$ glutaraldehyde in 0.1 $\mathrm{M}$ sodium cacodylate buffer at $\mathrm{pH}$ 7.3. The sample was then loaded on a carbon-coated electron microscopy grid and stained with $2 \%$ methylamine tungstate for 45 second and air-dried before exosome samples were observed in a JEM-1230 electron microscope.

\section{Endothelial cell proliferation assay}

HUVEC proliferation was determined using a MTS assay (CellTiter 96 AQueous One Solution Cell Proliferation Assay Kit, Promega), following the manufacturer's instructions. HUVECs were purchased from ATCC (Manassas, VA, USA) and cultured in endothelial cell growth medium (ECGM) (Cell Applications). HUVECs were seeded into 96-well plates at an initial density of $2 \times 10^{3}$ cells/well and incubated at $37^{\circ} \mathrm{C}$ for $12 \mathrm{~h}$. After synchronization with $2 \%$ FBS for $24 \mathrm{~h}$, cells were co-cultured with $\mathrm{CdM}^{\mathrm{MSC}}$ for $24,48,72$, and $96 \mathrm{~h}$, respectively. A curve of cell proliferation was constructed by measuring cell growth with a microplate M3 spectrophotometer (Molecular Devices) at $490 \mathrm{~nm}$.

\section{Angiogenesis models}

Three angiogenic models were used in this study: 1$)$ Tube-like structure formation: HUVECs $\left(3 \times 10^{4}\right.$ cells/ well) were seeded on top of Matrigel (BD Biosciences) in a 24-well plate and treated with the CdM (CdM-fresh medium, $1: 1)$ or exosomes $(100 \mu \mathrm{g} / \mathrm{ml})$ for $16 \mathrm{~h}$. Images were taken on a phase-contrast microscope (Olympus), and the cumulative tube length of the network structure was quantified by randomly selecting five microscopic fields (4× magnification) using Image J software. 2) Spheroidbased sprout: Endothelial-cell spheroids were generated as described previously [55] with minor modifications. In brief, GFP ${ }^{+}$HUVECs (500 cells/spheroid) were suspended in ECGM containing $0.2 \%$ carboxymethylcellulose (Sigma) and seeded in non-adherent round-bottom 96-well plates (Greiner) overnight. Spheroids were generated and embedded into Matrigel for $16 \mathrm{~h}$ in the presence of CdM (CdM-fresh medium, 1:1), or endothelial cell serum free defined medium (Cell Applications) only. Images were taken with an Olympus digital camera under Olympus BX 41 microscope. Capillary sprouting was quantified by measuring the cumulative length using Image $\mathrm{J}$ software from 10 to 15 spheroids. 3) Matrigel plug assay: Matrigel plug was performed as described previously [41], with minor modifications. Matrigel (BD Biosciences, $500 \mu \mathrm{l}$ ) containing $15 \mathrm{U}$ of heparin (Sigma) was mixed with DMEM, CdM (derived from $3 \times 10^{6} \mathrm{MSCs}$ ) or exosomes $(100 \mu \mathrm{g} / \mathrm{plug})$. C57BL6 mice (6- to 8-week-old) were anesthetized with ketamine/xylazine $(100 / 10 \mathrm{mg} / \mathrm{kg}, \mathrm{IP})$ and then subcutaneously injected with Matrigel along the abdominal midline. After 2 weeks, animals were sacrificed using over dose of anesthetic. Plugs were excised, embedded in O.C.T. and sections were cut at $7 \mu \mathrm{m}$. The infiltration of endothelial cells was determined by immunostaining for CD31. The images were photographed using an Olympus BX 71 microscope equipped with a digital camera (Olympus). Image-J software was used to measure CD31 positive cells in each field. The 
hemoglobin content of the Matrigel plugs was determined using Drabkin's reagent kit (Sigma, St Louis, MO) after the Matrigel plug was homogenized in deionized water and centrifuged to obtain the supernatant. The standard curve was generated using Stanbio ${ }^{\mathrm{TM}}$ Cyanmethemoglobin Standard (Stanbio Laboratory, Boerne, TX).

\section{Non-contact cell co-culture}

MSCs were non-contact co-cultured with HUVECs using Corning ${ }^{\circledR} \quad$ Transwell $^{\circledR} \quad(75 \mathrm{~mm}$ polycarbonate membrane cell culture insert, $0.4 \mu \mathrm{m}$ pore; Corning Inc). HUVECs were seeded onto the bottom of the plate at $1 \times 10^{6}$ per dish and cultured in ECGM. MSCs were seeded and pre-cultured onto the insert at $1 \times 10^{6}$. The next day, the insert was placed into the plate pre-cultured with HUVECs. The medium was replaced by serumfree DMEM medium for $48 \mathrm{~h}$. The culture medium was collected and concentrated into $100 \times$. In addition, MSCMSC and HUVEC-HUVEC co-culture were prepared as parallel control groups, respectively.

\section{Internalization of exosomes}

Exosomes were labeled using PKH26 (red) according to manufacturer's instructions (SigmaAldrich) [54] and added into the HUVEC culture at a concentration of $100 \mu \mathrm{g} / \mathrm{ml}$. The plate was placed into the IncuCyte ZOOM Live Content Imaging System (ESSEN BIOSCIENCE) installed inside an incubator and recorded every $2 \mathrm{~h}$ for $12 \mathrm{~h}$.

\section{Real-time PCR}

Total RNA was isolated from concentrated CdM, exosomes, MSCs, and HUVECs using miRNeasy Micro Kit (Qiagen). Briefly, $200 \mu \mathrm{CdM}$, exosome pellet or cell pellet was lysed by $1 \mathrm{ml}$ QIAzol Lysis Reagent. After $5 \mathrm{~min}$ incubation for homogeneity, $3.5 \mu \mathrm{l}$ of Spike-In control (ce-miR-39, $1.6 \times 10^{8}$ copies/ $\mu$ l working solution, Qiagen) were added, mixed thoroughly, and shaken for 15 seconds and then $200 \mu \mathrm{l}$ of chloroform were added. The mixture was centrifuged for 15 minutes at $12,000 \times \mathrm{g}$ at $4^{\circ} \mathrm{C}$ following incubation for $2 \mathrm{~min}$. Subsequent upper aqueous phase extraction and filter cartridge work were performed following manufacturer's instructions. cDNA synthesis and quantitative PCR was performed using miScript PCR Starter Kit (Qiagen). In brief, $1 \mu \mathrm{g}$ total RNA from each preparation was used for the first-strand cDNA reverse transcription in the $20 \mu$ system. Real-time PCR was performed with specific primers in iQ5 realtime PCR system (Bio-Rad) according to miScript SYBR Green PCR Starter Kit's recommendations. Data were normalized to results obtained with primers specific for U6 or in case of CdM and exosomes using synthetic Spike-In control (Ce-miR-39) as an internal control.

\section{Overexpression and knockdown of miR-30b in MSCs and HUVECs}

A lentiviral system was used to attain effective overexpression of miR-30b in MSCs and HUVECs. The pre-miR-30b-copGFP expression plasmid and scramble-copGFP control were purchased from System Biosciences Company. miR-30b plasmid or scrambled plasmid and packaging plasmids were co-transfected into 293 Ta cells according to manufacturer's instruction for production of high titer lentiviral particles. MSCs and HUVECs were infected with the generated high titer lentiviral particles for $24 \mathrm{~h}$. The cell pools were selected by puromycin after several infection times. In addition, synthetic anti-miR-30b (Ambion) was transfected into MSCs using Lipofectamine ${ }^{\mathrm{TM}}$ RNAiMAX (Invitrogen) to downregulate the expression of miR-30b in MSCs. The synthetic negative miR was used as control.

\section{Western blotting}

Western blotting was performed as described previously [56]. Briefly, cells and exosomes were lysed by RIPA buffer containing PMSF (Qiagen) and quantified with BCA protein assay reagent (Thermo Fisher Scientific). Approximately $30 \mu \mathrm{g}$ of total protein per lane were loaded. After electrophoresis, proteins were transferred to polyvinylidene fluoride membranes (Millipore). All membranes were then blocked with 5\% skim milk in TBST at room temperature for $1 \mathrm{~h}$ and incubated with the following primary antibodies: antiCD9 (Abcam), anti-CD63 (Applied Biological Materials), anti-HSP70 (Cell Signaling) and anti-DLL4 (Millipore), at $4^{\circ} \mathrm{C}$ overnight. After washing three times with TBST, the membranes were probed with appropriate HRP-conjugated secondary antibodies (Cell Signaling) at room temperature for $1 \mathrm{~h}$ and visualized using ECL Plus kit (GE Healthcare).

\section{Statistical analysis}

All data of in vitro experiments were obtained from at least three independent experiments. In in vivo study, more than 6 samples were used in each group. The results were presented as Means \pm SD unless otherwise indicated and were analyzed using SPSS 18.0 software. Statistical analyses were performed using a two-tailed Student $t$-test or one-way ANOVA with post-hoc tests to determine significant differences between groups. $P<0.05$ was considered statistically significant.

\section{ACKNOWLEDGMENTS AND FUNDING}

Research reported in this publication was supported by the National Heart, Lung, And Blood Institute of the National Institutes of Health under Award Number R01HL105176, and R01HL114654 and R01HL126516. 


\section{CONFLICTS OF INTEREST}

No conflicts of interest, financial or otherwise, are declared by the author(s).

\section{REFERENCES}

1. Zhao X, Balaji P, Pachon R, Beniamen DM, Vatner DE, Graham RM, Vatner SF. Overexpression of Cardiomyocyte alpha1A-Adrenergic Receptors Attenuates Postinfarct Remodeling by Inducing Angiogenesis Through Heterocellular Signaling. Arterioscler Thromb Vasc Biol. 2015; 35:2451-9.

2. Hoffmann CJ, Harms U, Rex A, Szulzewsky F, Wolf SA, Grittner U, Lattig-Tunnemann G, Sendtner M, Kettenmann H, Dirnagl U, Endres M, Harms C. Vascular signal transducer and activator of transcription-3 promotes angiogenesis and neuroplasticity long-term after stroke. Circulation. 2015; 131:1772-82.

3. Annex BH. Therapeutic angiogenesis for critical limb ischaemia. Nat Rev Cardiol. 2013; 10:387-96.

4. Silvestre JS. Pro-angiogenic cell-based therapy for the treatment of ischemic cardiovascular diseases. Thromb Res. 2012; 130:S90-4.

5. Suresh SC, Selvaraju V, Thirunavukkarasu M, Goldman JW, Husain A, Alexander PJ, Sanchez JA, McFadden DW, Maulik N. Thioredoxin-1 (Trx1) engineered mesenchymal stem cell therapy increased pro-angiogenic factors, reduced fibrosis and improved heart function in the infarcted rat myocardium. Int J Cardiol. 2015; 201:517-28.

6. Uemura R, Xu M, Ahmad N, Ashraf M. Bone marrow stem cells prevent left ventricular remodeling of ischemic heart through paracrine signaling. Circ Res. 2006; 98:1414-21.

7. Xu M, Uemura R, Dai Y, Wang Y, Pasha Z, Ashraf M. In vitro and in vivo effects of bone marrow stem cells on cardiac structure and function. J Mol Cell Cardiol. 2007; 42:441-8.

8. van Velthoven CT, Sheldon RA, Kavelaars A, Derugin N, Vexler ZS, Willemen HL, Maas M, Heijnen CJ, Ferriero DM. Mesenchymal stem cell transplantation attenuates brain injury after neonatal stroke. Stroke. 2013; 44:1426-32.

9. Lee JS, Hong JM, Moon GJ, Lee PH, Ahn YH, Bang OY. A long-term follow-up study of intravenous autologous mesenchymal stem cell transplantation in patients with ischemic stroke. Stem Cells. 2010; 28:1099-106.

10. Daley GQ, Scadden DT. Prospects for stem cell-based therapy. Cell. 2008; 132:544-8.

11. Satija NK, Singh VK, Verma YK, Gupta P, Sharma S, Afrin F, Sharma M, Sharma P, Tripathi RP, Gurudutta GU. Mesenchymal stem cell-based therapy: a new paradigm in regenerative medicine. J Cell Mol Med. 2009; 13:4385-402.

12. Cochain C, Channon KM, Silvestre JS. Angiogenesis in the infarcted myocardium. Antioxid Redox Signal. 2013; 18:1100-13.
13. Rahbarghazi R, Nassiri SM, Ahmadi SH, Mohammadi E, Rabbani S, Araghi A, Hosseinkhani H. Dynamic induction of pro-angiogenic milieu after transplantation of marrowderived mesenchymal stem cells in experimental myocardial infarction. Int J Cardiol. 2014; 173:453-66.

14. Kinnaird T, Stabile E, Burnett MS, Lee CW, Barr S, Fuchs S, Epstein SE. Marrow-derived stromal cells express genes encoding a broad spectrum of arteriogenic cytokines and promote in vitro and in vivo arteriogenesis through paracrine mechanisms. Circ Res. 2004; 94:678-85.

15. Ascheim DD, Gelijns AC, Goldstein D, Moye LA, Smedira N, Lee S, Klodell CT, Szady A, Parides MK, Jeffries NO, Skerrett D, Taylor DA, Rame JE, et al. Mesenchymal precursor cells as adjunctive therapy in recipients of contemporary left ventricular assist devices. Circulation. 2014; 129:2287-96.

16. Zuo S, Jones WK, Li H, He Z, Pasha Z, Yang Y, Wang Y, Fan GC, Ashraf M, Xu M. Paracrine effect of Wnt11overexpressing mesenchymal stem cells on ischemic injury. Stem Cells Dev. 2012; 21:598-608.

17. Thery C, Zitvogel L, Amigorena S. Exosomes: composition, biogenesis and function. Nat Rev Immunol. 2002; 2: 569-79.

18. Keller S, Sanderson MP, Stoeck A, Altevogt P. Exosomes: from biogenesis and secretion to biological function. Immunol Lett. 2006; 107:102-8.

19. Mathivanan S, Ji H, Simpson RJ. Exosomes: extracellular organelles important in intercellular communication. J Proteomics. 2010; 73:1907-20.

20. Valadi H, Ekstrom K, Bossios A, Sjostrand M, Lee JJ, Lotvall JO. Exosome-mediated transfer of mRNAs and microRNAs is a novel mechanism of genetic exchange between cells. Nat Cell Biol. 2007; 9:654-9.

21. Tadokoro H, Umezu $T$, Ohyashiki $K$, Hirano $T$, Ohyashiki JH. Exosomes derived from hypoxic leukemia cells enhance tube formation in endothelial cells. J Biol Chem. 2013; 288:34343-51.

22. Yu B, Kim HW, Gong M, Wang J, Millard RW, Wang Y, Ashraf M, Xu M. Exosomes secreted from GATA-4 overexpressing mesenchymal stem cells serve as a reservoir of anti-apoptotic microRNAs for cardioprotection. Int $\mathrm{J}$ Cardiol. 2015; 182:349-60.

23. Chen TS, Lai RC, Lee MM, Choo AB, Lee CN, Lim SK. Mesenchymal stem cell secretes microparticles enriched in pre-microRNAs. Nucleic Acids Res. 2010; 38: 215-24.

24. Das S, Halushka MK. Extracellular vesicle microRNA transfer in cardiovascular disease. Cardiovasc Pathol. 2015; 24:199-206.

25. Hulsmans M, Holvoet P. MicroRNA-containing microvesicles regulating inflammation in association with atherosclerotic disease. Cardiovasc Res. 2013; 100:7-18.

26. Stoorvogel W. Functional transfer of microRNA by exosomes. Blood. 2012; 119:646-8.

27. Krol J, Loedige I, Filipowicz W. The widespread regulation of microRNA biogenesis, function and decay. Nat Rev Genet. 2010; 11:597-610. 
28. Alvarez-Garcia I, Miska EA. MicroRNA functions in animal development and human disease. Development. 2005; 132:4653-62.

29. Wang S, Olson EN. AngiomiRs--key regulators of angiogenesis. Curr Opin Genet Dev. 2009; 19:205-11.

30. Ghosh G, Subramanian IV, Adhikari N, Zhang X, Joshi HP, Basi D, Chandrashekhar YS, Hall JL, Roy S, Zeng Y, Ramakrishnan S. Hypoxia-induced microRNA-424 expression in human endothelial cells regulates HIF-alpha isoforms and promotes angiogenesis. J Clin Invest. 2010; $120: 4141-54$

31. Bridge G, Monteiro R, Henderson S, Emuss V, Lagos D, Georgopoulou D, Patient R, Boshoff C. The microRNA-30 family targets DLL4 to modulate endothelial cell behavior during angiogenesis. Blood. 2012; 120:5063-72.

32. Kosaka N, Iguchi H, Yoshioka Y, Takeshita F, Matsuki Y, Ochiya T. Secretory mechanisms and intercellular transfer of microRNAs in living cells. J Biol Chem. 2010; 285:17442-52.

33. Ratajczak MZ, Kucia M, Jadczyk T, Greco NJ, Wojakowski W, Tendera M, Ratajczak J. Pivotal role of paracrine effects in stem cell therapies in regenerative medicine: can we translate stem cell-secreted paracrine factors and microvesicles into better therapeutic strategies. Leukemia. 2012; 26:1166-73.

34. EL AS, Mager I, Breakefield XO, Wood MJ. Extracellular vesicles: biology and emerging therapeutic opportunities. Nat Rev Drug Discov. 2013; 12:347-57.

35. Bussche L, Van de Walle GR. Peripheral Blood-Derived Mesenchymal Stromal Cells Promote Angiogenesis via Paracrine Stimulation of Vascular Endothelial Growth Factor Secretion in the Equine Model. Stem Cells Transl Med. 2014; 3:1514-25.

36. Yao X, Liu Y, Gao J, Yang L, Mao D, Stefanitsch C, Li Y, Zhang J, Ou L, Kong D, Zhao Q, Li Z. Nitric oxide releasing hydrogel enhances the therapeutic efficacy of mesenchymal stem cells for myocardial infarction. Biomaterials. 2015; $60: 130-40$.

37. Welten SM, Goossens EA, Quax PH, Nossent AY. The multifactorial nature of microRNAs in vascular remodelling. Cardiovasc Res. 2016; 110:6-22.

38. Kuehbacher A, Urbich C, Zeiher AM, Dimmeler S. Role of Dicer and Drosha for endothelial microRNA expression and angiogenesis. Circ Res. 2007; 101:59-68.

39. Spees JL, Lee RH, Gregory CA. Mechanisms of mesenchymal stem/stromal cell function. Stem Cell Res Ther. 2016; 7:125.

40. Creemers EE, Tijsen AJ, Pinto YM. Circulating microRNAs: novel biomarkers and extracellular communicators in cardiovascular disease. Circ Res. 2012; 110:483-95.

41. Mocharla P, Briand S, Giannotti G, Dorries C, Jakob P, Paneni F, Luscher T, Landmesser U. AngiomiR-126 expression and secretion from circulating CD34(+) and
CD14(+) PBMCs: role for proangiogenic effects and alterations in type 2 diabetics. Blood. 2013; 121:226-36.

42. Wang $\mathrm{X}, \mathrm{Gu} \mathrm{H}$, Huang W, Peng J, Li Y, Yang L, Qin D, Essandoh K, Wang Y, Peng T, Fan GC. Hsp20-Mediated Activation of Exosome Biogenesis in Cardiomyocytes Improves Cardiac Function and Angiogenesis in Diabetic Mice. Diabetes. 2016; 65:3111-28.

43. Geiger A, Walker A, Nissen E. Human fibrocyte-derived exosomes accelerate wound healing in genetically diabetic mice. Biochem Biophys Res Commun. 2015; 467:303-9.

44. Eirin A, Riester SM, Zhu XY, Tang H, Evans JM, O'Brien D, van Wijnen AJ, Lerman LO. MicroRNA and mRNA cargo of extracellular vesicles from porcine adipose tissue-derived mesenchymal stem cells. Gene. 2014; 551:55-64.

45. Jiang Q, Lagos-Quintana M, Liu D, Shi Y, Helker C, Herzog W, le Noble F. miR-30a regulates endothelial tip cell formation and arteriolar branching. Hypertension. 2013; 62:592-8.

46. Phng LK, Gerhardt H. Angiogenesis: a team effort coordinated by notch. Dev Cell. 2009; 16:196-208.

47. Suchting S, Freitas C, le Noble F, Benedito R, Breant C, Duarte A, Eichmann A. The Notch ligand Delta-like 4 negatively regulates endothelial tip cell formation and vessel branching. Proc Natl Acad Sci USA. 2007; 104:3225-30.

48. van Balkom BW, de Jong OG, Smits M, Brummelman J, den Ouden K, de Bree PM, van Eijndhoven MA, Pegtel DM, Stoorvogel W, Wurdinger T, Verhaar MC. Endothelial cells require miR-214 to secrete exosomes that suppress senescence and induce angiogenesis in human and mouse endothelial cells. Blood. 2013; 121:3997-4006, S1-15.

49. Zhang B, Wu X, Zhang X, Sun Y, Yan Y, Shi H, Zhu Y, Wu L, Pan Z, Zhu W, Qian H, Xu W. Human umbilical cord mesenchymal stem cell exosomes enhance angiogenesis through the Wnt4/beta-catenin pathway. Stem Cells Transl Med. 2015; 4:513-22.

50. Wang X, Huang W, Liu G, Cai W, Millard RW, Wang Y, Chang J, Peng T, Fan GC. Cardiomyocytes mediate antiangiogenesis in type 2 diabetic rats through the exosomal transfer of miR-320 into endothelial cells. J Mol Cell Cardiol. 2014; 74:139-50.

51. Barile L, Moccetti T, Marbán E, Vassalli G. Roles of exosomes in cardioprotection. Eur Heart J. 2017; 38:1372-1379.

52. Toh WS, Lai RC, Hui JH, Lim SK. MSC exosome as a cellfree MSC therapy for cartilage regeneration: Implications for osteoarthritis treatment. Semin Cell Dev Biol. 2016; 67: 56-64.

53. Konala VB, Mamidi MK, Bhonde R, Das AK, Pochampally R, Pal R. The current landscape of the mesenchymal stromal cell secretome: A new paradigm for cell-free regeneration. Cytotherapy. 2016; 18:13-24.

54. Yu B, Gong M, Wang Y, Millard RW, Pasha Z, Yang Y, Ashraf M, Xu M. Cardiomyocyte protection by GATA4 gene engineered mesenchymal stem cells is partially mediated by translocation of miR-221 in microvesicles. PLOS ONE. 2013; 8:e73304. 
55. Diehl F, Rossig L, Zeiher AM, Dimmeler S, Urbich C. The histone methyltransferase MLL is an upstream regulator of endothelial-cell sprout formation. Blood. 2007; 109:1472-8.

56. Yu B, Gong M, He Z, Wang YG, Millard RW, Ashraf M, $\mathrm{Xu}$ M. Enhanced mesenchymal stem cell survival induced by GATA-4 overexpression is partially mediated by regulation of the miR-15 family. Int J Biochem Cell Biol. $2013 ; 45: 2724-35$. 